\title{
Jogada ensaiada: representações sociais da figura do goleiro no futebol brasileiro pós Barbosa
}

\section{Set piece: social representations of the goalkeeper figure in Brazilian football post-Barbosa}

Felipe Freddo Breunig ${ }^{1,}$ Douglas Meyer Oliveira², Alex Branco Fraga²

${ }^{1}$ Universidade Federal do Rio Grande do Norte (UFRN), Natal, Brasil

${ }^{2}$ Universidade Federal do Rio Grande do Sul (UFRGS), Porto Alegre, Brasil

\section{HISTÓRICO DO ARTIGO \\ Recebido: 01 julho 2021 \\ Revisado: 16 agosto 2021 \\ Aprovado: 17 agosto 2021}

\section{PALAVRAS-CHAVE:}

Futebol; Goleiro;

Representações.

\section{KEYWORDS:}

Soccer; Goalkeeper;

Representations.

\section{RESUMO}

INTRODUÇÃO: Este ensaio aborda as representações sociais em torno do papel do goleiro no contexto do futebol brasileiro. O marco temporal é a Copa do Mundo de 1950 pelo impacto histórico e sociocultural que a derrota da seleção brasileira na final no Maracanã teve no cenário nacional à época.

OBJETIVO: Analisa dados e informações de alguns autores sobre a Copa do mundo daquele ano, especialmente sobre a falha do goleiro Barbosa, que foi culpado pela derrota brasileira na final daquela Copa.

MÉTODOS: Análise interpretativa de discursos sobre goleiros na ótica da Teoria do Espaço de Representação do Futebol.

CONCLUSÃO: Conclui que no Brasil, desde o episódio Barbosa, construiu-se uma representação de fundo racista sobre a confiabilidade de goleiros negros, assim como uma exacerbada valorização de goleiros estrangeiros. Discute possíveis caminhos a serem seguidos em pesquisas futuras nesta temática.

\section{ABSTRACT}

BACKGROUND: TThis essay addresses the social representations surrounding the role of the goalkeeper in the context of Brazilian football. The time frame is the 1950 World Cup due to the historical and sociocultural impact that the defeat of the Brazilian team in the final at Maracanã Stadium had on the national scene at the time.

OBJECTIVE: It analyzes data and information from some authors about the World Cup of that year, especially about the failure of goalkeeper Barbosa, who was held responsible for the Brazilian defeat in the final of that Cup.

METHODS: Interpretative analysis of discourses about goalkeepers from the perspective of the Football Representation Space Theory.

CONCLUSION: It concludes that in Brazil, since the Barbosa episode, a representation of racist background has been built on the reliability of black goalkeepers, as well as an exacerbated appreciation of foreign goalkeepers. It discusses possible paths to be followed in future research on this topic. 


\section{PRELEÇÃO}

\section{Aspectos Introdutórios}

O goleiro é um dos personagens mais excêntricos dentro do cenário futebolístico. Sua atuação vai contra toda a lógica do futebol: enquanto toda dinâmica de jogo que envolve os demais jogadores gira em torno do objetivo maior dentro do esporte (marcar gols), a maioria dos gestos do goleiro em uma partida visa impedir este momento. Além disso, só a ele é permitido tocar na bola com as mãos, fazendo com que o caráter contraditório de sua existência dentro do jogo seja mais acentuado.

Dadas as características do fazer do goleiro dentro do contexto futebolístico, é possível inferir que a evidência de sua atuação dentro de um jogo se dará mais facilmente quando falhar em exercer o seu objetivo. Ou seja, o produto de seus êxitos é nulo dentro da dinâmica do jogo (defesas não contam pontos ou gols), enquanto o produto do seu fracasso em exercer sua função é positivo (gols para o adversário). A lógica é oposta em comparação com os demais jogadores. Sendo assim, enquanto a maioria dos jogadores é lembrada pelos gols que fez, o goleiro geralmente é lembrado pelos gols que não conseguiu evitar. Estando sua imagem geralmente atrelada aos momentos em que não obteve êxito em sua ação, é de certa forma compreensível que a responsabilidade pelo gol sofrido tenda a recair sobre ele. Como afirmou Galeano, "o goleiro sempre tem culpa, e se não tem, paga do mesmo jeito" (GALEANO, 2016, p. 8).

A partir deste raciocínio, é possível afirmar que nenhum goleiro ficou tão presente no imaginário coletivo dos brasileiros quanto Barbosa, goleiro titular da seleção brasileira na Copa de 1950 e eleito pela mídia nacional como o principal responsável pela derrota do Brasil frente ao Uruguai na final daquela Copa. Até a final daquele torneio mundial de seleções, nunca a atuação de um goleiro tinha sido tão comentada no Brasil por torcedores e pela mídia.

Aquela Copa do Mundo, realizada em terras brasileiras, representava uma importância fundamental para a nação, por inúmeros motivos políticos, culturais e esportivos. Logo, o fracasso da seleção não foi apenas o fracasso de um time de futebol. Foi a falência de toda uma tentativa de afirmação da autoestima de um país, a qual teve como principal culpado, segundo a mídia da época, o goleiro negro Barbosa, acusado de ter falhado no segundo gol dos adversários uruguaios na final daquele torneio. Punido injustamente durante toda sua vida pelo "Maracanazo", Moacir Barbosa Nascimento sintetizou sua condição após aquela fatídica final, conforme relatado por Guilherme (2006, p. 109), da seguinte forma: "No Brasil, a pena máxima (de prisão) é de 30 anos, mas pago há 40 por um crime que não cometi."

Considerando o futebol um elemento sociocultural, construtor de uma espacialidade própria, cuja dinâmica social influencia e é influenciada pela sociedade que o vivencia, este ensaio objetiva abordar as diferentes representações atribuídas à figura do goleiro, após a imagem construída pela mídia nacional do goleiro Barbosa. A partir de representações construídas por dada sociedade, são criados estereótipos sobre determinada função sociocultural na qual são definidos quais indivíduos são aptos ou capazes de desenvolver esta função. Por isso, o resultado da análise das representações sociais do goleiro pode transcender as quatro linhas do campo de futebol, dizendo um pouco da cultura e das crenças da sociedade que as construíram.
No ano de 2021 estamos comemorando o centenário do nascimento de Barbosa, e mais uma vez sua imagem vem à tona na imprensa em geral. A despeito da brilhante carreira que este goleiro teve, e dos títulos que conquistou, inevitavelmente o seu nome evoca memórias relacionadas com a derrota do Brasil na Copa de 1950, e a sua consequente culpabilização pelo segundo gol uruguaio. Tal acontecimento ficou tão arraigado no imaginário coletivo brasileiro, que até os dias atuais estas questões reverberam e retornam, o que torna atual e relevante discutir sobre representações sociais da figura do goleiro relacionadas com estes fatos. Exemplo disso pode ser evidenciado durante uma fala no programa Fox Sports Rádio, em que o comentarista e ex-jogador de futebol Edílson afirma que "goleiro negão sempre toma um gol" (FERREIRA, 2018).

Esse ensaio visa contribuir com apontamentos capazes de suscitar um maior interesse por pesquisas a respeito da figura e do papel do goleiro no futebol por parte da comunidade acadêmica que pesquisa este esporte, seja no campo geral das ciências humanas, ou no campo específico das representações sociais. Em pesquisa realizada no Google Acadêmico em agosto de 2021 com o termo "goleiro de futebol", dos 224 resultados encontrados somente 8 trabalhos se propõem a problematizar o papel do goleiro de futebol sob aspectos que não sejam relativos a características técnicas e táticas do jogo.

Nota-se facilmente que a maioria esmagadora dos estudos que tematizam o goleiro de futebol ocupa-se de aspectos relacionados as diferentes perspectivas e metodologias de treinamento específico existentes, o que evidencia uma carência de estudos sob o prisma das Ciências Humanas. Também não foi encontrado nenhum artigo que abordasse representações sociais criadas em torno da figura do goleiro, o que sinaliza uma importante lacuna a ser preenchida, capaz de trazer maior arejamento para o campo de estudos das representações sociais no futebol.

O percurso metodológico deste ensaio inicialmente parte de uma abordagem acerca da relação do goleiro com o contexto de jogo do futebol. Em seguida, são analisadas algumas produções acadêmicas e jornalísticas que abordam a derrota brasileira na Copa de 1950, e a consequente culpabilização do goleiro Barbosa. A partir dessa análise, foram traçados possíveis aspectos de relacionamento entre a culpabilização de Barbosa pela derrota do Brasil na Copa de 50 e as representações sociais acerca da figura do goleiro no futebol brasileiro desde então. A interpretação dos diferentes dados encontrados se deu a partir do conceito de "espaço de representação do futebol". Este conceito foi desenvolvido por Campos (2006), visando a apreensão do futebol como um elemento sociocultural e espacial.

\section{ENTENDENDO 0 JOGO}

\section{A teoria do espaço de representação do futebol}

O futebol ocupa um lugar de destaque na vida diária de miIhões de pessoas em todo Brasil. O esporte não mobiliza apenas aqueles que trabalham de uma forma direta ou indireta com ele, mas também inúmeros indivíduos que possuem algum vínculo afetivo e emocional com esta prática. Jogadores, técnicos, jornalistas e torcedores são alguns dos personagens envolvidos nesta trama de relações que transcende o campo de jogo. Desta maneira, é necessário um aporte teórico que contemple as 
múltiplas facetas deste universo, para que se possa entender a dinâmica de suas relações.

Neste sentido, a teoria do espaço de representação do futebol, desenvolvida por Campos (2006), parece a mais adequada para embasar o propósito deste ensaio. Ela compreende o futebol como um espaço de representações sociais constituídas através da interação de diversos atores socioespaciais, que formam complexas relações. Estes atores são classificados em três categorias principais: profissionais, especialistas e torcedores.

São considerados profissionais todos aqueles que interferem diretamente no jogo (jogadores, técnicos, dirigentes, árbitros). Na categoria dos especialistas estão incluídos aqueles que trabalham com a mídia esportiva (narradores, repórteres, comentaristas, jornalistas). A terceira categoria proposta por Campos (2006), a dos torcedores, inclui todos aqueles que possuem algum vínculo afetivo com alguma instituição futebolística. Em relação à essa terceira categoria, o autor entende que através do encontro entre torcedores, seja ele nos estádios ou até em espaços públicos como bares ou praças, é possível que as representações sociais surjam ou se modifiquem, de modo que esses estereótipos criados comecem a circular e que sejam constantemente redefinidos, assim como os aspectos ligados à própria prática social do futebol, como os significados e forma de torcer.

Basicamente, as representações sociais no futebol são construídas a partir do contato direto entre os torcedores e entre os profissionais. Mas também são construídas representações através da incorporação de discursos elaborados por especialistas. O modo de falar, a entonação da voz, repetir diversas vezes o nome de um atleta, ou até mesmo a interpretação de um lance feita de forma equivocada por um narrador de rádio, por exemplo, pode criar representações sociais que nem sempre sejam verdadeiras, mas que dependendo da situação podem vir a se tornar.

\section{E 0 JOGO COMEÇA}

\section{0 goleiro no contexto do futebol}

Alguns anos separam a invenção do futebol moderno da criação da figura do goleiro. Somente em 1871 estabeleceu-se que um jogador poderia pegar a bola com as mãos no então chamado "football". Desde então, o esporte nunca mais foi o mesmo, pois "[...] o goleiro tornou-se o referencial para a evolução do futebol" (GUILHERME, 2006, p. 25).

A partir de um olhar mais cuidadoso, dentro de uma perspectiva antropológica, Franco Júnior (2007) mostra um certo sentido sacrificial para a existência do goleiro dentro do futebol. Afirma que ele precisa ser "morto" para que haja sentido no jogo. Apenas quando o goleiro for vencido completamente é que o jogo terá o seu momento ápice: o gol. É ele o guardião do objetivo último do adversário.

Não por acaso que o goleiro pode ser considerado o " $[. .$. bode expiatório simbólico por excelência [...]" (FRANCO JÚNIOR, 2007, p. 249) em uma partida de futebol. Sendo sua função exclusiva impossibilitar o gol do adversário, é compreensível que aconteça uma associação da ocorrência do mesmo com a sua figura. Durante uma partida de futebol, é comum os torcedores atribuírem a ocorrência de um gol do time adversário a uma possível falha do goleiro da equipe da qual simpatizam.

No texto "Futebol, Camus e a solidão do goleiro", de Acácio
Augusto (2008), o autor define a posição de goleiro como ingrata, afirmando que na parte onde ele pisa sequer nasce grama, e o goleiro como sendo um sujeito solitário, pois desempenha uma função totalmente diferente dos demais jogadores, tendo assim responsabilidades distintas dentro do jogo. Considerando-se as perspectivas espacial e temporal, o goleiro passa a maior parte do tempo de jogo de uma maneira solitária, situado embaixo ou próximo das traves. O autor frisa que, ao mesmo tempo que a solidão do goleiro faz com que ele carregue sozinho a culpa de uma falha ou de uma derrota, é ela também que possibilita uma defesa que garanta a vitória da sua equipe, tornando a distância entre o heroísmo e o fracasso muito curta.

Para que seja possível compreender de modo amplo a condição do goleiro no futebol, convém apresentar o ponto de vista de quem encarna e vive esse personagem no cenário futebolístico. Em seu trabalho intitulado "Goleiros: Heróis e Anti-Heróis da camisa 1", Paulo Guilherme (2014) relata uma entrevista de um dos maiores goleiros de todos os tempos, Gylmar dos Santos Neves, onde ele afirma que o goleiro vive uma solidão terrível e afirma que não tem nada a ver com os outros dez jogadores em campo, ganhando desta forma um destaque multiplicado; ao fazer uma defesa, não fez mais que o seu dever, porém uma pequena falha pode se transformar numa tragédia.

Outra entrevista que é citada também em seu trabalho, é a do ex-goleiro e hoje técnico Émerson Leão, na qual ele afirma que o goleiro trabalha para que não ocorra o que todo mundo quer que aconteça: o gol. Ele afirma que o goleiro joga contra o êxtase do torcedor, e evidencia que é por isso que todo o goleiro é um vencedor solitário. Percebemos, então, que a solidão não está relacionada apenas ao fato de o goleiro utilizar vestimentas diferentes e ter permissões especiais para atuar durante o jogo, mas nas responsabilidades que Ihe são atribuídas, tais como a defesa de um pênalti ou a falha em um lance específico que define o resultado de uma partida, sendo o causador da vitória ou da derrota.

A partir destas inferências acerca do simbolismo do goleiro na dinâmica do futebol, é possível entender a imagem idealizada que existe sobre suas qualidades. Ao goleiro são atribuídas características fundamentais (tanto por torcedores, quanto por profissionais), dentre as quais destacam-se: confiabilidade, coragem, inteligência, responsabilidade e tranquilidade. Estes que atuam na posição produzem fatos futebolísticos, os quais servirão de base para a formulação de representações sociais pelos torcedores, segundo a perspectiva utilizada de Campos (2006).

O fato futebolístico pode ser apontado como elemento original do
espaço de representação do futebol, pois sem ele os outros não
fariam sentido. Ele é a partida, o próprio jogo de futebol, ou seja, o
ritual. É a partir do fato futebolístico: que as pessoas, os grupos e
as comunidades formulam as representações sociais; que os dife-
rentes atores do espaço de representação do futebol se relacionam
e produzem seus discursos; que os símbolos e mitos são gerados;
enfim, que toda a malha de significados que permeia o futebol é
criada (CAMPOS, 2018, p. 5).

O autor ainda afirma que, a partir do fato futebolístico, acontece o relacionamento entre os diferentes atores do espaço de representação do futebol, bem como a produção de discursos, a geração de símbolos e a construção de mitos. Assim, é possível visualizar que os discursos construídos a partir de símbolos e mitos, originários de diferentes fatos futebolísticos, irão servir de alicerce para representações sociais da figura do 
goleiro, as quais poderão influenciar na escolha de determinados sujeitos (ou grupo de sujeitos) que exercerão esta função dentro do jogo.

\section{UM LANCE DECISIVO E UMA JOGADA ENSAIADA A derrota na Copa de 50 e a culpabilização de Barbosa}

Um dos acontecimentos dotados de maior simbolismo no âmbito do futebol brasileiro foi a derrota do Brasil na Copa de 50, frente a seleção do Uruguai. A partir deste momento, foi construído todo um complexo de inferioridade não só sobre a seleção, mas também no que dizia respeito a raça e ao futuro do país: "A perda do título mundial em pleno território nacional fez com que cada copa do mundo se tornasse uma oportunidade (quase um dever) da seleção, ou melhor, do Brasil se mostrar capaz para o mundo" (CAMPOS, 2006, p. 44).

Inúmeras eram as explicações criadas pela imprensa que procuravam justificar o fracasso da seleção brasileira. Aquelas que atribuíam a derrota à composição racial da equipe merecem especial atenção, já que as mesmas se embasaram em veIhas teorias racistas do século 19 , que afirmavam uma suposta inferioridade do negro. Segundo Rodrigues (2020), recuperou-se, inclusive, uma teoria específica criada durante o período do Estado Novo (1937-1945), a qual afirmava uma suposta inferioridade do brasileiro enquanto raça, devido à forte miscigenação existente em nosso país.

Mário Filho confirma estes aspectos em seu livro "O Negro no Futebol Brasileiro" (2003), ao se referir à reação brasileira frente à derrota para o Uruguai, quando afirma que "uns acusavam [o técnico] Flávio Costa. Mas quase todos se viravam era contra os pretos do escrete" (p. 289). Porém, o goleiro negro Barbosa foi eleito o principal culpado pela derrota, acusado de falhar no gol que definiu a vitória da equipe uruguaia. A dupla condição de negro e goleiro fez com que Barbosa ficasse marcado para sempre no imaginário do torcedor brasileiro como o responsável pela derrota da seleção nacional.

Jornais da época tentaram associar a suposta falha no lance decisivo com a sua raça. Todo um discurso racial foi construído, o qual tentava eleger como causa principal do fracasso do goleiro (bem como de toda seleção) a uma suposta falta de coragem inerente a sua cor:

O problema da raça brasileira reaparecia de forma aguda, reforçando o complexo de inferioridade existente. Para muitos discursos racistas, a composição étnica havia definido a sorte de nossa seleção assim como definia a sorte da própria sociedade. Mesmo sabendo-se que Obdúlio Varela, o grande capitão uruguaio e destaque do jogo final, era mulato (FRANCO JÚNIOR, 2007, p. 91)

Nos anos seguintes, os poucos goleiros negros convocados nunca conseguiram se firmar como titulares na seleção brasileira, além de ter suas carreiras marcadas pela culpabilização em lances decisivos, segundo afirma Coelho (2012). O jornalista lembra que Veludo, goleiro do Fluminense, foi convocado em 1954, porém foi reserva naquela Copa, e dois anos depois ficou marcado por uma falha em um jogo do campeonato carioca, a qual levou a direção do clube a reduzir em $60 \%$ o seu salário, o que teria contribuído para a abreviação de sua carreira, e posteriores problemas com alcoolismo. Também lembra a falha em um gol do goleiro pardo Manga na Copa de 1966, em um jogo contra Portugal, a qual foi explicada na época como sendo causada por um desequilíbrio emocional inerente a sua cor da pele.

Tais discursos tiveram repercussão tão grande, que levou anos para que um goleiro negro assumisse novamente a titularidade na seleção brasileira. Isto ocorreu somente na Copa de 2006, quando o goleiro Dida assumiu a titularidade no torneio daquele ano. Depois, somente em 2014 houve outro goleiro negro na equipe, o goleiro Jeferson, que foi reserva naquela competição, o que demonstra uma proporção bem menor de negros goleiros, se comparados com jogadores de outras posições. Uma análise subjetiva feita pelo jornalista Paulo Guilherme (2014), com fotos de jogadores dos clubes que disputaram os campeonatos brasileiros de 2004 e 2005, corrobora com este dado. Enquanto o percentual de jogadores não-goleiros que eram negros ou pardos girava em torno de $43 \%$, o percentual de goleiros negros não ultrapassou os $18 \%$.

Segundo Franco Junior (2007), nas duas décadas seguintes a Copa de 50, vários grandes clubes do futebol brasileiro passaram a contratar goleiros estrangeiros para jogar em suas equipes. O que de fato mostra que o fracasso de Barbosa não só atingiu os goleiros que tinham sua cor, mas também os goleiros brasileiros de uma maneira geral.

Fica evidente que o simbolismo construído em torno do discurso produzido pela mídia sobre Barbosa, a partir da final da Copa do Mundo de 1950, influenciou a formação de representações sociais da figura do goleiro no cenário futebolístico nacional. Tais representações não foram incorporadas apenas por torcedores, mas também por profissionais, visto que suas repercussões perpassaram o campo do imaginário e do simbólico, vindo a constituir-se em uma realidade objetiva.

\section{O JOGO (NÃO) TERMINA AQUI}

O futebol, enquanto elemento sociocultural, é produto das relações entre diversos atores socioespaciais, que ao relacionarem-se entre si constroem variadas representações. No contexto específico do campo de jogo, a prática do goleiro possui características próprias bem diferenciadas dos demais jogadores. A importância de sua existência dentro da dinâmica de uma partida favorece na idealização de sua imagem.

A partir de fatos que acontecem em jogos de futebol são construídos mitos e símbolos, que servem de base para a construção de representações. A partir do sentido simbólico dado a imagem de Barbosa após a Copa de 50, há claros indícios empíricos acerca da construção de representações sociais racistas e estrangeiristas sobre o goleiro no Brasil. Contudo, seria incorreto afirmar que tais representações não existiam antes de Barbosa. Guilherme (2014) traz indícios de que antes de Barbosa já não havia aceitação de negros na posição de goleiro, ao mostrar que desde o primeiro jogo da seleção, em 1914, até 2006, dos 92 goleiros que foram convocados, apenas 12 eram negros e pardos.

Tal constatação indica que representações racistas em torno da figura do goleiro negro não começaram com o gol que Barbosa tomou na final da Copa de 50. Também nos aponta que o racismo não deve ser compreendido somente a partir de um fato isolado de um contexto específico de um esporte, já que ele é estrutural e historicamente arraigado no nosso país, como nos diz Almeida (2018): 
O racismo não é um ato ou um conjunto de atos e tampouco se resume a um fenômeno restrito às práticas institucionais; é, sobretudo, um processo histórico e político em que as condições de subalternidade ou de privilégio de sujeitos racializados é estruturalmente reproduzida (ALMEIDA, 2018, p. 45).

Desta forma, há de se considerar que o futebol se constitui no interior de uma sociedade que é estruturalmente racista. $E$ que este racismo presente nas diversas esferas da vida social também se reproduz no âmbito do futebol, manifestando-se na figura do goleiro, mas também atingindo jogadores negros de todas posições.

Há uma lacuna aqui de estudos de representações sociais a partir do que foi explicitado desde então nos discursos construídos pelos especialistas e incorporados por torcedores, e também acerca da influência destes discursos e representações na realidade sócio-espacial do futebol brasileiro. Além dos discursos que circulam entre especialistas e torcedores, também seria interessante investigar as representações sociais da figura do goleiro entre os jogadores profissionais, inclusive entre os próprios goleiros.

É importante observar que sempre há uma continuidade temporal da repercussão de discursos produzidos no passado. Ou seja, por mais que aqueles que presenciaram, discutiram, enfim, que vivenciaram a Copa do Mundo de 1950 estejam em sua maioria mortos, as opiniões, preconceitos e visões de mundo constituídas naquele momento permanecem vivas, inclusive talvez ainda fornecendo subsídios para representações de goleiros no espaço do futebol na atualidade. Neste sentido, cabe a seguinte pergunta: A cruz que outrora Barbosa teve que carregar permaneceu (e permanece) nos ombros dos que trazem a sua cor e que ocuparam (e ocupam) a sua posição?

Nesse sentido, também é pertinente lembrar que em 2014 tivemos novamente uma copa do mundo sendo realizada em terras brasileiras, onde a seleção do Brasil foi eliminada nas semifinais pela Alemanha, num histórico 7 a 1 que pegou a todos de surpresa. Uma situação de vexame e vergonha nacional muito semelhante ao ocorrido na Copa de 1950 (ou talvez até pior), todavia, houve a diferença de não ter havido a culpabilização de nenhum jogador. Consequentemente, também não houve a construção de explicações que buscassem associar erros individuais a algum estereótipo grupal.

Em coluna publicada na revista Carta Capital em 2014, Djamila Ribeiro lembra que quando um indivíduo de um grupo historicamente discriminado erra, todo o grupo é culpabilizado. $\mathrm{E}$ de maneira muito perspicaz, arremata: "Júlio César, goleiro da seleção [...] obviamente não foi culpado pela derrota da seleção brasileira para a alemã por 7 a 1, a culpa não foi dele, é todo um time que joga, mas não se ouviu ninguém dizer que homens brancos são 'frangueiros', por exemplo. Nenhum mito criou-se em cima do goleiro branco" (RIBEIRO, 2015).

As questões levantadas neste ensaio envolvendo as representações sociais da figura do goleiro a partir de Barbosa (e para além dele) podem ser melhor refletidas a partir de outras análises e metodologias que se detenham de forma mais aprofundada a estes aspectos. Também seria profícuo analisar tais aspectos a partir de diferentes recortes geográficos e históricos no Brasil, ou seja, a partir das múltiplas realidades sócio-espaciais que compõem este país.

Existem discursos atuais sobre a figura do goleiro que podem ser relacionados com o simbolismo da Copa de 1950? Como estas representações manifestam-se na prática amadora do futebol? Estas são algumas das questões que podem nortear futuros trabalhos a respeito desta instigante temática, que em muito pode contribuir para uma melhor compreensão do futebol em suas dinâmicas sócio-históricas e antropológicas.

\section{REFERÊNCIAS}

ALMEIDA, S. L. O que é racismo estrutural? Belo Horizonte: Letramento, 2018.

CAMPOS, F. R. G. O espaço de representação do futebol: uma apreensão do futebol como um elemento sociocultural e espacial. Curitiba: UFPR, 2006.

CAMPOS, F. R. G. O conceito de espaço de representação do futebol como possibilidade para apreensão do futebol profissional e amador como fenômenos da espacialidade. Boletim de Geografia, Maringá, v. 36, n. 2, p. 1-13, 2018.

COELHO, R. D. Presença de goleiros negros no Brasil salta de $12,5 \%$ para $31 \%$ em oito anos. UOL, 2012. Disponível em: <http://www.uol.com. br/esporte/futebol/ultimas-noticias/2012/11/17/presenca-de-goleirosnegros-aumenta-mas-eles-ainda-sao-minoria.htm>. Acessado em: 22 de junho de 2021

FERREIRA, E. Edílson revolta palmeirenses ao opinar sobre Jailson: “Goleiro negão falha”. In: Fox Sports Rádio, 2018. Disponível em: < http:// uolesportevetv.blogosfera.uol.com.br/2018/02/16/edilson-revoltapalmeirenses-ao-opinar-sobre-jailson-goleiro-negao-falha/>. Acessado em: 24 de junho de 2021.

FRANCO JUNIOR, H. F. A dança dos deuses: futebol, cultura, sociedade. São Paulo: Companhia das Letras, 2007.

GUILHERME, P. Goleiros: heróis e anti-heróis da camisa 1. São Paulo: Alameda, 2006

RIBEIRO, D. A vingança de Barbosa: a luta do goleiro negro por respeito. Carta Capital, 2015. Disponível em: <http://observatorioracialfutebol. com.br/a-vinganca-de-barbosa-a-luta-do-goleiro-negro-por-respeito/>. Acessado em: 24 de junho de 2021.

RODRIGUES, B Estigma racista do goleiro negro persiste desde derrota na Copa de 1950. Folha de São Paulo, 2020. Disponível em: <http://www1. folha.uol.com.br/esporte/2020/07/estigma-racista-do-goleiro-negropersiste-70-anos-apos-maracanazo.shtml>. Acessado em 22 de junho de 2021

RODRIGUES FILHO, M. L. O negro no futebol brasileiro. Rio de Janeiro: Mauad, 2003.

\section{AGRADECIMENTOS}

Às universidades públicas brasileiras.

\section{CONFLITO DE INTERESSE}

Os autores do estudo declaram não haver conflito de interesses.

\section{ORCID E E-MAIL DOS AUTORES}

Felipe Freddo Breunig

ORCID: 0000-0003-3057-8260.

E-mail: felipebreunig@yahoo.com.br

Douglas Meyer Oliveira (Autor Correspondente)

ORCID: 000-0001-6479-6499.

E-mail: douglas_poa@hotmail.com 


\section{FINANCIAMENTO}

O presente trabalho foi realizado com apoio da Coordenação de Aperfeiçoamento de Pessoal de Nível Superior - Brasil (CAPES) - Código de Financiamento 001.
Alex Branco Fraga

ORCID: 0000-0002-6881-1446.

E-mail: brancofraga@gmail.com 